\title{
THE EFFECTS OF BACK-STEP FOOTWORK ON TAEKWONDO ROUNDHOUSE KICK FOR THE COUNTERATTACK
}

\author{
Taewoon Jung ${ }^{1}$; Hyoungjin Park ${ }^{2}$
}

1. Jeonju Kijeon College, Korea.

2. Korea Science Academy of KAIST, Korea.

\begin{abstract}
The roundhouse kick is the most often used kick in Taekwondo sparring matches. In order to execute the effective kicks, footwork is critical. Therefore, the purpose of this study was to biomechanically examine the effects of backstep-footwork on the Taekwondo roundhouse kick for the counterattack. Ten male university Taekwondo athletes executed roundhouse kicks with five counterattack footwork conditions. The duration of the phases of the kick, the center of mass displacement, trunk, right hip, right knee angles, and kicking thigh, shin, foot, and toe velocities were obtained through a three-dimensional video motion analysis. These variables were compared to the conditions using repeated measure analysis of variance, and changed significantly in response to different footwork conditions. It was concluded that as the footwork distance increased, the center of the body became lower, the trunk angle reduced, the kick-leg increased foot speed. Therefore, it would be necessary to make efforts to compensate for the strengths and weaknesses of the various types of kicks that are used to invalidate the opponent's attack and to increase the contribution of each body segment.
\end{abstract}

Keywords: taekwondo roundhouse kick, biomechanics, footwork

\section{LOS EFECTOS DEL TRABAJO DE PIES DE RETROCESO EN LA PATADA GIRATORIA DE TAEKWONDO PARA EL CONTRAATAQUE}

\begin{abstract}
RESUMEN
La patada giratoria es la patada más utilizada en los combates de Taekwondo. Para la ejecución efectiva de las patadas, el juego de pies es crítico. Por lo tanto, el propósito de este estudio fue examinar biomecánicamente los efectos del nivel de juego de pies en la patada giratoria de Taekwondo para el contraataque. Diez atletas universitarios masculinos de Taekwondo ejecutaron patadas giratorias con cinco condiciones de contraataque. La duración de las fases de la patada, el desplazamiento del centro de masas, los ángulos del tronco, la cadera derecha, la rodilla derecha y las velocidades de patada en muslo, espinilla, pie y dedo del pie se obtuvieron a través de un análisis de movimiento de video tridimensional. Estas variables se compararon en diferentes condiciones de juego de pies mediante el análisis de varianza de medidas repetidas, cambiando significativamente en respuesta a diferentes condiciones de trabajo de pies. Se concluyó que a medida que aumentaba la distancia del trabajo de pies, el centro de masas descendía, el ángulo del tronco se reducía, la pierna de patada aumentaba la velocidad del pie. Por lo tanto, sería necesario hacer esfuerzos para compensar las fortalezas y debilidades de los diversos tipos de patadas que se utilizan para invalidar el ataque del oponente y aumentar la contribución de cada segmento del cuerpo.

Palabras clave: patada circular de taekwondo, biomecánica, juego de pies
\end{abstract}

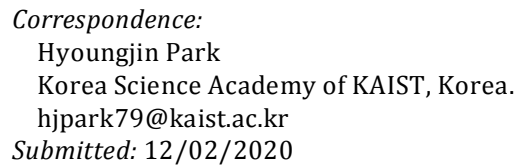

Accepted: 19/06/2020 


\section{INTRODUCTION}

Taekwondo is a martial art and a full-contact combat sport that is characterized by various kicking techniques. Taekwondo athletes execute kicking more frequently than punching, and more than $90 \%$ of the points are recorded by kicks in Taekwondo sparring matches (Kazemi, Perri, \& Soave, 2010) because of the larger target area, longer reaching distance of legs compared to arms, and a greater impact force compared to that of punches (Kim, Kwon, Yenuga, \& Kwon, 2010). Among the kicking techniques, the roundhouse kick (dollyochagi or bandalchagi) is the most often used in Taekwondo competitions (Koh \& Watkinson, 2002). The roundhouse kick is suitable for attacks and counterattacks and has a short execution time (Kim, Kwon, Yenuga, \& Kwon, 2010). In addition, the roundhouse kick is the fastest kicking technique (Pieter \& Pieter, 1995) and is useful for scoring points in an unexpected attack (Kim et al., 2010). The roundhouse kick in particular can be easily adjusted based on the opponent's movement during a competition (Falco et al., 2009). Studies on the roundhouse kick have investigated a wide range of biomechanical variables such as kicking speed (Liu, Tan, An, \& Wang, 2000; Tang, Chang, \& Nien, 2007), execution time (Estevan, Alvarez, Falco, MolinaGarcia, \& Castillo, 2011; Falco et al., 2009; Liu, Tan, An, \& Wang, 2000; Tang, Chang, \& Nien, 2007), and impact force (Estevan, Alvarez, Falco, Molina-Garcia, \& Castillo, 2011; Estevan et al., 2012; Falco et al., 2009). Researchers have also explored the following participant characteristics: weight category (Estevan et al., 2012) and skill level (Shin \& Choi, 2001). In terms of trial conditions that affect performance, previous studies analyzed the effects of the existence of a target (Oh \& Choi, 2004), the proximity of the kicking foot (Kong, Luk, \& Hong, 2000), stance positions (Estevan, Falco, \& Jandacka, 2011), and dominant leg (Falco et al., 2009; Tang, Chang, \& Nien, 2007). However, scientific knowledge on taekwondo kicks is still quite limited especially, knowledge is needed about other factors that can affect kicking performance, such as the footwork. Footwork for counterattack is a critical performance that should be preceded before kicking, but to date, there has not been an analysis of the roundhouse kick along with the associated footwork. Taekwondo athletes should move rapidly to establish a favorable position and to obtain time and space during the sparring using step movements which define as footwork in this study, then are able to gain tactical advantage. Taekwondo sparring has dynamics in which attacks, counterattacks and defenses instantly switch. For instance, the kicking involved is not only intended for an attack but is also used in the technique of blocking the attack or converting the defense back into an attack at the same time (i.e., counterattack). For this reason, the footwork could be more important than the kick itself, and the roundhouse kick's adjustability can be one of its main strengths that makes it possible to execute this particular kick 
with various kinds of footwork. Menescardi and colleagues (2015) found that winners in the National University Taekwondo Championship used more counterattacks, which meant that Taekwondo athletes may need to perform the counterattack as efficiently as possible to score points. During a sparring match, Taekwondo athletes can often be forced to execute kicks by reacting to the opponent's attack, and in this counterattack process, the connection between the footwork and the kick execution is critical for the kick performance (Kim, Chung, \& Lee, 1999). Therefore, researchers need to analyze counterattacking footwork and attack motions simultaneously. Studying counterattacks using roundhouse kicks that are executed from post-defense footwork may provide a better understanding of the ideal counterattacking footwork for roundhouse kick performance and practical training methods. The purpose of this study was to biomechanically examine the effects of counterattack footwork that was used for the counterpart's attack in Taekwondo roundhouse kick performances. The research questions were: 1) How would different footwork change the duration time and the distance of the center of mass?; 2) How would footwork change the trunk, thigh, and knee angles?; 3) How would footwork change the kicking thigh, shin, foot, and toe's velocities? It was hypothesized that the footwork would affect the temporal and spatial parameters of Taekwondo athletes.

\section{METHOD}

\section{Participants}

A group of ten male university Taekwondo athletes were recruited through University Taekwondo department for this study. All participants were selected as Taekwondo athletes with more than 7 years of Taekwondo training experience. All participants were free of serious muscular or joint/ligament problems within 6 months prior to the study. Informed consent was obtained from all participants before the experiment. The study followed the policy statement with respect to the Declaration of Helsinki and was approved by the university's Review Board. Participant characteristics are presented in Table 1.

TABLE 1

Presenting characteristics of $\mathrm{OA}$ and control participants.

\begin{tabular}{cccccc}
\hline \hline & Age (yr) & Height (cm) & Mass (kg) & BMI (kg/m2) & Career (yr) \\
\hline Mean (S.D.) & $21.7 \pm 0.5$ & $173.1 \pm 4.3$ & $60.6 \pm 3.7$ & $20.2 \pm 0.6$ & $8.9 \pm 1.1$ \\
Range & $21-22$ & $167-179$ & $54.9-66.7$ & $19.3-21.1$ & $7-10$ \\
\hline \hline
\end{tabular}

\section{Instrumentation}

An MX-13 Vicon ${ }^{\mathrm{TM}}$ motion capture system (Vicon, Ltd., Oxford, UK), including seven high-speed cameras (Sampling frequency: $250 \mathrm{~Hz}$ ) and MX 
control interfaces, was used to record the locations of the reflective markers on the participants' bodies. A calibration frame with 36 markers (1m wide, $2 \mathrm{~m}$ high, and $2 \mathrm{~m}$ long) was used for the calibration based on the Direct Linear Transformation (DLT) method. The calibration frame was aligned so that the kicking direction was used as the anteroposterior axis (Y) while the longitudinal axis (Z) was aligned vertically upward, and the horizontal axis (X) was aligned left to right. The 37 retro-reflective markers were placed at the following anatomical locations (Figure 1): the left and right forehead (LFHD, RFHD) ; left and right back of the head (LBHD, RBHD); the 7th cervical vertebrae (C7); the 10th thoracic vertebrae (T10); the clavicle (CLAV); sternum (STRN); the right scapula (RBAC); the left and right shoulder at the acromioclavicular joint (LSHO, RSHO); the lateral epicondyle of the left and right elbow (LELB, RELB); the left and right forearm between the elbow and wrist (LFRM, RFRM); the medial and lateral left wrist (LWRA, LWRB); the medial and lateral right wrist (RWRA, RWRB); the left and right hand second metacarpal head (LFIN, RFIN); the left and right anterior superior iliac spine (LFWT, RFWT); the left and right posterior superior iliac spine (LBWT, RBWT); the left and right lateral aspect middle of thigh (LTHI, RTHI); the lateral epicondyle of the left and right knee (LKNE, RKNE); lateral aspect middle of shank (LSHN, RSHN); the left and right lateral malleolus (LANK, RANK); the left and right foot first metatarsal head (LTOE, RTOE); and the left and right heel placed on the calcaneous (LHEE, RHEE). The marker coordinates were used to model the body with a combination of several rigid segments connected by frictionless joints, including each pelvis, trunk, right thigh, right lower leg, and foot segments. The target was a double-handed target mitt. An assistant held the target, and the target height was set at waist level for the roundhouse kick performances. One reflective marker was positioned on the target in order to find the onset of the foot contact with the target. 

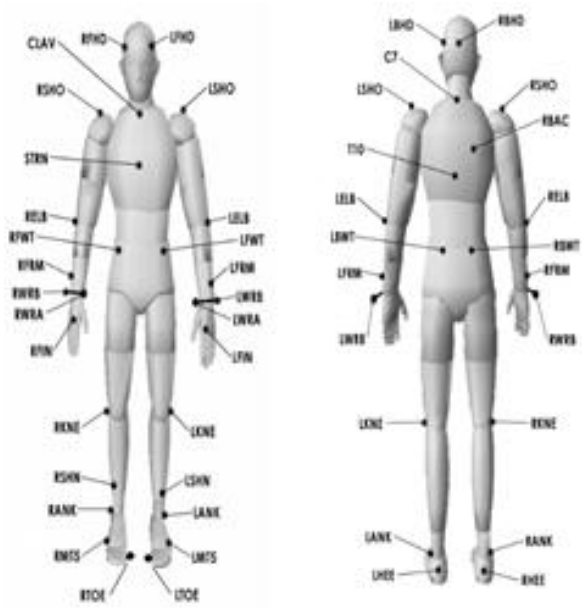

FIGURE 1: Anterior (Left) and posterior (Right) views of the reflective markers.

\section{Experimental procedure}

Before the data collection, a static trial was recorded with the participant standing in the anatomical position with medial markers. The medial markers (medial epicondyles and malleoli) were detached after the static trial was finished in order to prevent any interference. Also, participants were allowed to warm up that included roundhouse kicks to familiarize themselves with the process of kicking the target. After the kicking warm-up, the participants engaged in their own preferred ways of stretching, stepping, and kicking. Because all participants were right-footed, the left leg was the support leg, while the right was the kicking leg in the trials. A double-handed target mitt was leveled to the participant's waist and tilted down slightly for an easy kick performance. For the counterattack footwork (backward steps), all of the participants practiced until they were accustomed to the specific lengths of the step-back. Then, the participants were asked to execute footwork followed by a roundhouse kick counterattack to hit the given target as fast as possible with the bare foot of their right leg immediately after the flashing LED light signaled the participants to start. Five trials were performed, and a 5-minute rest was given before data collection for the next trial.

\section{Trial conditions}

Five footwork conditions were used (Figure 2): the roundhouse kick without footwork, preferred-distance-backstep (PB) roundhouse kick, shortdistance-backstep (SB), long-distance-backstep (LB), double-backstep (DB), and double-backward-step with cross feet step (CBS). The average of five trial' backstep distances was calculated in order to define the distance of PB. Following Kim et al. (2010), SB distance was calculated by subtracting 30\% 
from the average value (PB), and LB was increased by $30 \%$. The DB and CBS used the LB distance ( $30 \%$ added distance). Therefore, footwork distances varied from one participant to another. Each participant performed twenty-five roundhouse kicks with footwork (five kicks per footwork condition) and the footwork conditions were randomized.

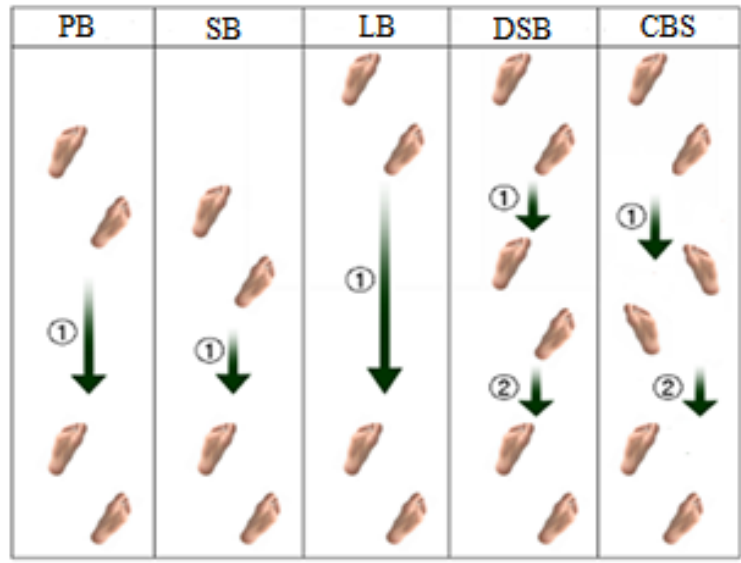

FIGURE 2: Types of Backstep Footworks.

\section{Data reduction and analysis}

For the data analysis, the following meaningful events were defined: Signal, Onset, Preliminary, Kicking, Maximum Knee Flexion (MKF), and Impact (Figure 3). Among the events, Onset (the beginning of the motion for footwork) was visually identified based on the velocities of the right toe and heel markers. Preliminary was defined as when the footwork was finished, and the participant was ready to kick. Kicking was defined as the moment when the kicking foot toe (right) left the ground (Estevan, Freedman-Silvernail, Jandacka, \& Falco, 2016). MKF was the frame point at which the kicking leg had maximum knee flexion. Impact was defined as the point in time at which the marker on the target began to move. In addition, five phases were defined based on the events: Reaction (Signal to Onset) $\rightarrow$ Footwork (Onset to Preliminary) $\rightarrow$ Toe-off (Preliminary to Kicking) $\rightarrow$ Flexion (Kicking to MKF) $\rightarrow$ Extension (MKF to Impact). 


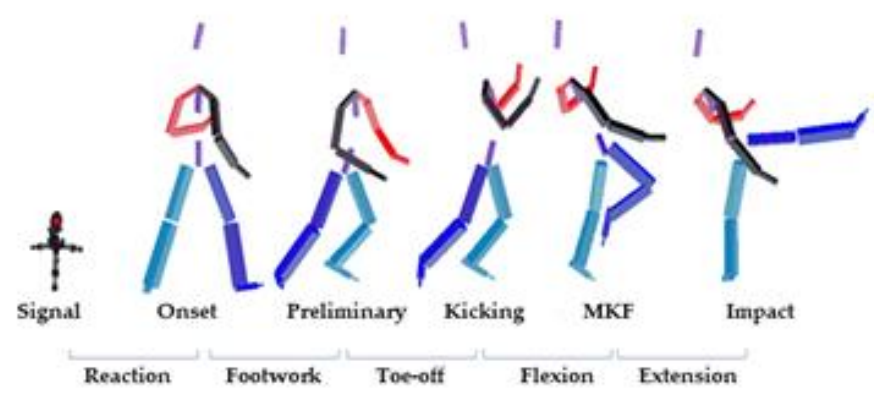

FIGURE 3: The roundhouse kick task and the events and phases of the kick.

Motion capture data were digitized to track reflective markers with the Kwon3D software. The three-dimensional coordinates of the reflective markers were generated via a DLT algorithm (Abdel-Aziz, Karara, \& Hauck, 2015) and were smoothed using an $8 \mathrm{~Hz}$ low-pass fourth-order Butterworth filter. The kinematic variables were the duration of the phases of the kick, joint and body angles, and center of mass displacement. The duration of the phases of the kick variable of the kicking performance was analyzed from the event of Preliminary to each event and total time. The duration of the phases of each kick variable was calculated using the following formula:

$$
t(i \sim f)=\left(F_{f}-F_{i}\right) \times \frac{1}{\text { frame rate, }}
$$

where $t(i \sim f)=$ the time required, $\mathrm{F}_{f}=$ the frame number of each event end, and $\mathrm{F}_{i}=$ the frame number of each event start. Additionally, the angular variable was the trunk angle, and the angle between two adjacent segments was obtained by using the dot product of the vector. That is, the angle $\theta$ between two vectors $U\left(X_{i}, Y_{i}, Z_{i}\right)$ and $V\left(X_{j}, Y_{j}, Z_{j}\right)$ was calculated using the following formula:

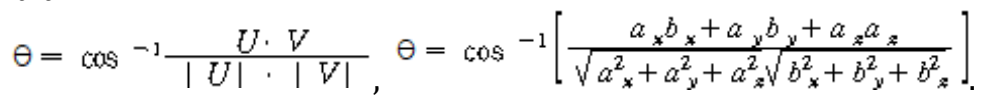




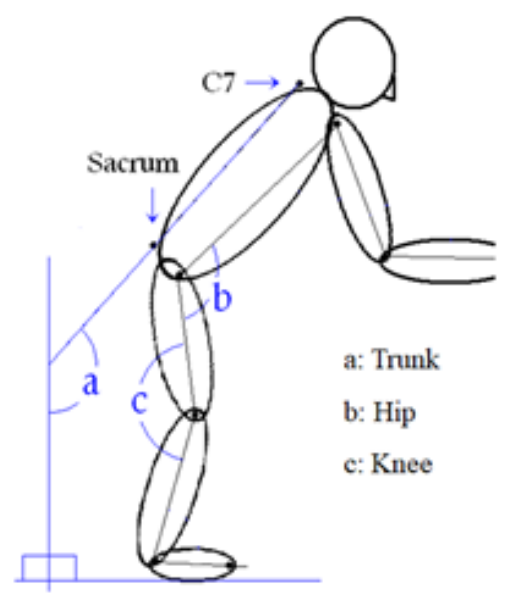

FIGURE 4: Definition of trunk, hip, and knee angle.

The linear velocity variables were the kicking leg's thigh, shin, and foot. The velocity was first calculated for each of the $\mathrm{X}, \mathrm{Y}$, and $\mathrm{Z}$ components using the following equation, and the $\mathrm{X}, \mathrm{Y}$, and $\mathrm{Z}$ components were synthesized in order to obtain the resultant velocity:

$$
X_{i=} \frac{X_{i+1}-X_{i-1}}{2 \Delta t}
$$

where $X_{i+1}$ : $i$-first $X$ coordinates, $X_{i+1}: I+$ first $X$ coordinates, and $X i: i^{\text {th }} X$ component velocity; and

$$
V=\sqrt{X_{i}^{\prime 2}+Y_{i}^{\prime 2}+Z_{i}^{\prime 2}}
$$

where $\mathrm{V}: i^{\text {th }}$ resultant velocity, $X_{i}^{\prime}$ : $i^{\text {th }} X$ component's velocity, $Y_{i}^{\prime}: i^{\text {th }} Y$ component's velocity, and $Z_{i}^{\prime}$ : $i^{\text {th }} Z$ component's velocity. The center of gravity coordinate $\left(C_{i}\right)$ of Segment $i$ was calculated by the following formula:

$$
c_{i}=\left(1-p_{i}\right) \cdot P_{i}+p_{i} \cdot D_{i}
$$

where $p_{i}$ : The ratio of the center-of-gravity distance from the proximal end to the segment length, and $P_{i}, D_{i}$ : Coordinates of segmental proximal and distal ends. The location of the center of mass was calculated by the following formula:

$$
\frac{\sum_{i}\left(c_{i} \cdot m_{i}\right)}{M}
$$

$m_{i}$ : Mass of the segment, and $M$ : Whole body mass

One-way repeated ANOVA with the footwork being a within-subject factor was used to compare dependent variables among the footwork conditions (PB, 
SB, LB, DB, and CBS). Post-hoc tests were conducted with the Bonferroni adjustment. Alpha was set at 0.05 in all statistical analyses.

\section{RESULTS}

The duration of the phases of the kick

The duration of the phases of the roundhouse kicks is shown in Table 2. The roundhouse kicks with PB took $1.09 \mathrm{sec}$ (roundhouse kick with PB), 1.27 sec (LB), $1.38 \mathrm{sec}$ (CBS), $1.00 \mathrm{sec}$ (SB), and $1.41 \mathrm{sec}(\mathrm{DB})$, respectively, and the duration of the phases of the kick increased significantly as the duration of time required by the Footwork phase increased.

TABLE 2

Duration of time required by each phase.

\begin{tabular}{ccccccc}
\hline \hline & Reaction & Footwork & Toe-off & Flexion & Extension & Total \\
\hline PB\#1 & $0.21 \pm 0.07$ & $0.54 \pm 0.06$ & $0.12 \pm 0.04$ & $0.11 \pm 0.02$ & $0.10 \pm 0.02$ & $1.09 \pm 0.14$ \\
LB\#2 & $0.24 \pm 0.08$ & $0.67^{\# 1} \pm 0.06$ & $0.16 \pm 0.05$ & $0.11 \pm 0.01$ & $0.10 \pm 0.01$ & $1.27 \pm 0.15$ \\
CBS\#3 & $0.24 \pm 0.03$ & $0.78^{\# 1} \pm 0.09$ & $0.16 \pm 0.07$ & $0.11 \pm 0.02$ & $0.10 \pm 0.01$ & $1.38^{\# 1} \pm 0.16$ \\
SB\#4 & $0.24 \pm 0.05$ & $0.47^{\# 2,3} \pm 0.10$ & $0.09 \pm 0.03$ & $0.10 \pm 0.02$ & $0.10 \pm 0.02$ & $1.00^{\# 2,3 \pm 0.16}$ \\
DB\#5 & $0.24 \pm 0.06$ & $0.78^{\# 1,4 \pm 0.12}$ & $0.17^{\# 4} \pm 0.08$ & $0.12 \pm 0.02$ & $0.10 \pm 0.02$ & $1.41^{\# 1,4} \pm 0.17$ \\
\hline f & .511 & 24.599 & 3.284 & .910 & .658 & 13.368 \\
sig. & .728 & $.000^{* * *}$ & $.019^{*}$ & .467 & .625 & $.000^{* * *}$ \\
\hline \hline
\end{tabular}

In the table, the notation "\#n" indicates a significant level $(p<0.05)$ between the corresponding types. (Unit: sec)

*** $: p<.001, *: p<.05$

As shown in Figure 5, when the required time was compared with the Toeoff, Flexion, and Extension phases except for the time required by the Reaction and Footwork phases, the roundhouse kick with DB took the longest amount of time at Toe-off. In addition, the shortest amount of time was $0.09 \mathrm{sec}$ in SB, and the LB and CBS were $0.16 \mathrm{sec}$. As the footwork distance reduced, the momentum also decreased; therefore, the kicking foot could move quickly after completing the footwork. 


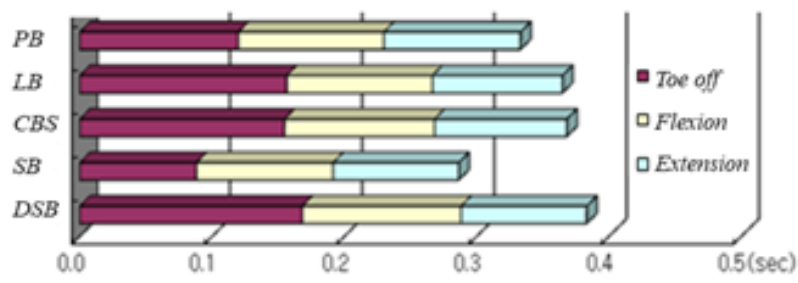

FIGURE 5: Comparison of duration of time required excluding Reaction and Back-step phases.

\section{The center of mass displacement}

As determined by examining the center of mass displacement in each phase of the roundhouse kick with $\mathrm{PB}$, the center of the mass moved about $3.1 \mathrm{~cm}$ toward the target point and the left side by $2.3 \mathrm{~cm}$ in the Toe-off phase in which the right foot left the ground. In the Flexion phase, the center of mass moved about $8.5 \mathrm{~cm}$ toward the target point, $2.5 \mathrm{~cm}$ to the left, and upward by $12.0 \mathrm{~cm}$. In the Extension phase, the center of mass moved about $9.2 \mathrm{~cm}$ to the target point, $2.3 \mathrm{~cm}$ to the left, and $3.4 \mathrm{~cm}$ upward. In the Footwork phase, the center of mass moved in the opposite direction from the target point in the y-axis-56.0 $\mathrm{cm}$ and in the z-axis $-13.6 \mathrm{~cm}$ in the Footwork phase, which meant that the center of mass was lowered due to knee bending in order to absorb the impulse that was generated by the movement. Assuming that Preliminary was the origin and upon converting the coordinate values, in the MKF event, the $\mathrm{x}^{-}, \mathrm{y}^{-}, \mathrm{z}$-axes were $-4.8 \mathrm{~cm}, 11.6 \mathrm{~cm}$, and $23.4 \mathrm{~cm}$, respectively; in the Impact event, the $\mathrm{x}-, \mathrm{y}-$, z-axes were $-7.1 \mathrm{~cm}, 20.8 \mathrm{~cm}$, and $26.8 \mathrm{~cm}$, respectively, which showed that the displacement in the vertical direction was larger than that in the horizontal displacement. Assuming that Preliminary was the origin and upon converting the composite center of mass displacement from Preliminary to Impact, LB, CBS, SB, DB were $39.4 \mathrm{~cm}, 40.0 \mathrm{~cm}, 26.6 \mathrm{~cm}$, and $39.9 \mathrm{~cm}$, respectively. In the Impact event, the height changes for the center of mass displacement were between $11.9 \mathrm{~cm}$ and $14.4 \mathrm{~cm}$ in all types of footwork. There were statistically significant differences in the forward and backward displacements of the center of mass as the distance of the footwork increased. 
TABLE 3

The center of mass displacements.

\begin{tabular}{|c|c|c|c|c|c|c|}
\hline & & Footwork & Toe-off & Flexion & Extension & Total \\
\hline \multirow{3}{*}{$\mathrm{PB}^{\# 1}$} & $\mathrm{x}$ & $4.3 \pm 3.5$ & $-2.3 \pm 1.3$ & $-2.5 \pm 1.0$ & $-2.3 \pm 0.8$ & $-2.8 \pm 4.5$ \\
\hline & $\mathrm{y}$ & $-56.0 \pm 8.8$ & $3.1 \pm 2.6$ & $8.5 \pm 2.2$ & $9.2 \pm 3.0$ & $-35.2 \pm 10.9$ \\
\hline & $\mathrm{z}$ & $-13.6 \pm 3.4$ & $11.4 \pm 2.2$ & $12.0 \pm 2.2$ & $3.4 \pm 1.2$ & $13.2 \pm 2.8$ \\
\hline \multirow{3}{*}{$\mathrm{LB}^{\# 2}$} & $\mathrm{x}$ & $4.1 \pm 2.6$ & $-3.1 \pm 1.3$ & $-3.0 \pm 1.7$ & $-2.3 \pm 1.0$ & $-4.2^{\# 1} \pm 3.6$ \\
\hline & $\mathrm{y}$ & $-81.8^{\# 1 \pm 7.3}$ & $4.8^{\# 1 \pm 2.3}$ & $9.3^{\# 1 \pm 1.2}$ & $9.0 \pm 1.9$ & $-58.8 \pm 6.5$ \\
\hline & $\mathrm{z}$ & $-17.6 \pm 3.2$ & $14.6 \pm 3.1$ & $12.5 \pm 2.2$ & $3.8 \pm 1.3$ & $13.3 \pm 2.5$ \\
\hline \multirow{3}{*}{$\mathrm{CBS}^{\# 3}$} & $\mathrm{x}$ & $-2.4 \pm 7.0$ & $-3.2^{\# 1} \pm 1.6$ & $-2.7^{\# 1} \pm 1.4$ & $-2.0 \pm 1.0$ & $-10.2 \pm 8.1$ \\
\hline & $\mathrm{y}$ & $-89.4^{\# 1} \pm 11.6$ & $6.8^{\# 1 \pm 4.0}$ & $11.7^{\# 1} \pm 3.1$ & $11.1^{\# 1} \pm 2.7$ & $-59.8^{\# 1} \pm 12.3$ \\
\hline & $\mathrm{z}$ & $-13.0 \pm 2.8$ & $11.0 \pm 3.3$ & $11.2 \pm 2.6$ & $3.5 \pm 1.3$ & $12.7 \pm 3.0$ \\
\hline \multirow{3}{*}{$\mathrm{SB}^{\# 4}$} & $x$ & $0.3 \pm 2.6$ & $-1.4 \pm 0.7$ & $-1.7 \pm 0.9$ & $-1.5 \pm 0.7$ & $-4.4 \pm 3.4$ \\
\hline & $\mathrm{y}$ & $-43.3 \# 2,4 \pm 13.3$ & $1.9 \# 2,3 \pm 1.6$ & $6.6^{\# 2,3 \pm 2.2}$ & $6.8^{\# 2,3 \pm 2.4}$ & $-27.9 \# 2,3 \pm 10.7$ \\
\hline & $\mathrm{z}$ & $-7.0 \# 1,2,3 \pm 3.2$ & $7.5 \pm 2.2$ & $10.5 \pm 1.4$ & $3.2 \pm 1.5$ & $14.2 \pm 3.2$ \\
\hline \multirow{3}{*}{$\mathrm{DB}^{\# 5}$} & $\mathrm{x}$ & $1.6 \pm 6.2$ & $-2.4 \pm 1.0$ & $-2.6 \pm 1.6$ & $-1.7 \pm 0.6$ & $-5.0 \pm 6.8$ \\
\hline & $\mathrm{y}$ & $-86.8^{\# 1,4 \pm 12.5}$ & $5.4 \# 1,4 \pm 3.0$ & $12.0^{\# 1,4} \pm 2.1$ & $10.6^{\# 1,4 \pm 3.1}$ & $-58.7 \# 1,4 \pm 14.4$ \\
\hline & $\mathrm{z}$ & $-14.5 \# 4 \pm 3.8$ & $11.5 \pm 2.6$ & $12.6 \pm 3.4$ & $3.3 \pm 1.5$ & $13.0 \pm 4.4$ \\
\hline \multirow{3}{*}{$f$} & $\mathrm{x}$ & 3.445 & 3.194 & 3.037 & 2.614 & 3.091 \\
\hline & $\mathrm{y}$ & 35.583 & 30.259 & 23.991 & 18.469 & 27.884 \\
\hline & $\mathrm{z}$ & 13.518 & 1.384 & .355 & .282 & 2.434 \\
\hline \multirow{3}{*}{ sig. } & $\mathrm{x}$ & $.015^{*}$ & $.022^{*}$ & $.027^{*}$ & $.048^{*}$ & $.025^{*}$ \\
\hline & $\mathrm{y}$ & $.000^{* * *}$ & $.000^{* * *}$ & $.000^{* * *}$ & $.000^{* * *}$ & $.000^{* * *}$ \\
\hline & $\mathrm{z}$ & $.000^{* * *}$ & .255 & .839 & .888 & .061 \\
\hline
\end{tabular}

In the table, the notation "\#n" indicates a significant level $(p<0.05)$ between the corresponding types. (Unit: $\mathrm{cm}$ )

***: $p<.001, *: p<.05$

\section{Trunk, Right hip, and Right knee angles}

As shown in Table 4, there were statistically significant differences in trunk and right hip, and right knee angles among the types of footwork in the Preliminary event of trunk, right hip, and right knee angles: PB $\left(155.4^{\circ}, 177.6^{\circ}\right.$, $\left.150.7^{\circ}\right)$, LB $\left(152.1^{\circ}, 162.0^{\circ}, 134.0^{\circ}\right)$, and $\operatorname{SB}\left(160.3^{\circ}, 190.1^{\circ}, 167.1^{\circ}\right)$, respectively. For the trunk angle in $\mathrm{PB}$, the upper body started with $155.4^{\circ}$ and increased until middle of Flexion phase. Then, the trunk angle began to decrease until the end. This change was thought to be the result of the body being pushed backward to kick farther in order to maintain the balance before the next movement. The right hip angle in the Toe-off phase start to expand rapidly, and the right hip angles were between $187.1^{\circ}$ to $192.2^{\circ}$ at the Kicking event. Then, hip flexion started from the Flexion phase to the end. Also, the right knee angles decreased as the distance of the footwork increased. 
TABLE 4

Trunk, Right Hip, and Right Knee Angles.

\begin{tabular}{ccccc}
\hline \hline Trunk & Preliminary & Kicking & MKF & Impact \\
\hline PB $^{\# 1}$ & $155.4 \pm 7.5$ & $166.5 \pm 5.6$ & $166.6 \pm 5.8$ & $159.9 \pm 7.9$ \\
LB\#2 & $152.1 \pm 5.6$ & $164.8 \pm 4.2$ & $168.4 \pm 6.7$ & $162.3 \pm 8.3$ \\
CBS\#3 & $153.8 \pm 6.0$ & $162.8 \pm 5.2$ & $166.6 \pm 6.8$ & $160.1 \pm 9.2$ \\
SB\#4 & $160.3 \# 2 \pm 5.4$ & $169.0 \# 3 \pm 2.6$ & $168.2 \pm 5.2$ & $160.5 \pm 7.3$ \\
DB\#5 & $154.8 \pm 4.6$ & $164.4 \pm 4.9$ & $166.5 \pm 6.6$ & $160.3 \pm 7.4$ \\
\hline$f$ & 2.723 & 2.741 & .207 & .107 \\
sig. & $.041^{*}$ & $.040^{*}$ & .933 & .979 \\
\hline Right Hip & Preliminary & Kicking & MKF & Impact \\
\hline PB\#1 & $177.6 \pm 19.9$ & $192.2 \pm 10.0$ & $167.4 \pm 12.0$ & $146.2 \pm 18.0$ \\
LB\#2 & $162.0 \pm 21.6$ & $187.1 \pm 9.7$ & $162.9 \pm 4.5$ & $139.2 \pm 20.2$ \\
CBS\#3 & $166.8 \pm 22.4$ & $190.6 \pm 10.8$ & $163.2 \pm 12.9$ & $144.4 \pm 19.5$ \\
SB\#4 & $190.1^{\# 2 \pm 13.4}$ & $191.1 \pm 8.9$ & $164.4 \pm 15.2$ & $144.9 \pm 18.4$ \\
DB\#5 & $166.3 \pm 18.8$ & $190.5 \pm 11.2$ & $165.5 \pm 15.1$ & $148.7 \pm 16.3$ \\
\hline$f$ & 3.406 & .356 & .174 & .356 \\
sig. & $.016 *$ & .839 & .951 & .838 \\
\hline Right Knee & Preliminary & Kicking & MKF & Impact \\
\hline PB\#1 & $150.7 \pm 17.6$ & $152.1 \pm 6.7$ & $83.8 \pm 8.5$ & $151.8 \pm 10.8$ \\
LB\#2 & $134.0 \pm 19.1$ & $143.2 \pm 11.8$ & $83.4 \pm 9.7$ & $152.6 \pm 13.3$ \\
CBS\#3 & $144.0 \pm 21.8$ & $149.4 \pm 11.3$ & $84.7 \pm 9.8$ & $149.0 \pm 8.8$ \\
SB\#4 & $167.1 \# 2 \pm 12.4$ & $146.2 \pm 8.8$ & $88.6 \pm 9.2$ & $153.3 \pm 14.2$ \\
DB\#5 & $140.5 \# 4 \pm 19.1$ & $150.9 \pm 12.1$ & $83.3 \pm 8.9$ & $152.5 \pm 20.0$ \\
\hline$f$ & 4.786 & 1.228 & .588 & .144 \\
sig. & $.003^{* *}$ & .313 & .673 & .965 \\
\hline \hline
\end{tabular}

In the table, the notation "\#n" indicates a significant level $(p<0.05)$ between the corresponding types. (Unit: degree)

**: $p<.01, *: p<.05$

\section{Kicking leg segment velocities}

As shown in Table 5, there were significantly velocity differences in thigh, shin, and foot segments at Preliminary. Thigh and shin velocities showed a gradual increase in the Toe-off phase and a decrease after MKF. However, foot velocity increased until just before Impact. 
TABLE 5

Kicking segments velocity.

\begin{tabular}{|c|c|c|c|c|}
\hline Thigh velocity & Preliminary & Kicking & MKF & Impact \\
\hline $\mathrm{PB}^{\# 1}$ & $0.67 \pm 0.26$ & $2.85 \pm 0.31$ & $3.88 \pm 0.41$ & $1.09 \pm 0.28$ \\
\hline $\mathrm{LB}^{\# 2}$ & $0.57 \pm 0.22$ & $3.05 \pm 0.34$ & $3.82 \pm 0.22$ & $1.10 \pm 0.20$ \\
\hline CBS\#3 & $0.32^{\# 1 \pm 0.11}$ & $2.89 \pm 0.38$ & $4.11 \pm 0.31$ & $1.31 \pm 0.22$ \\
\hline $\mathrm{SB}^{\# 4}$ & $0.62 \pm 0.36$ & $2.90 \pm 0.40$ & $3.58^{\# 3} \pm 0.36$ & $1.10 \pm 0.41$ \\
\hline $\mathrm{DB}^{\# 5}$ & $0.51 \pm 0.22$ & $2.90 \pm 0.33$ & $3.90 \pm 0.30$ & $1.36 \pm 0.34$ \\
\hline$f$ & 2.958 & .460 & 3.380 & 1.522 \\
\hline sig. & $.030^{*}$ & .765 & $.017^{*}$ & .212 \\
\hline Shin velocity & Preliminary & Kicking & MKF & Impact \\
\hline $\mathrm{PB}^{\# 1}$ & $0.59 \pm 0.35$ & $3.56 \pm 0.77$ & $7.51 \pm 0.53$ & $5.34 \pm 0.70$ \\
\hline $\mathrm{LB}^{\# 2}$ & $0.37 \pm 0.17$ & $3.83 \pm 0.57$ & $7.48 \pm 0.55$ & $5.06 \pm 0.58$ \\
\hline $\mathrm{CBS}^{\# 3}$ & $0.27 \pm 0.13$ & $3.60 \pm 0.77$ & $7.83 \pm 0.51$ & $5.42 \pm 0.77$ \\
\hline $\mathrm{SB}^{\# 4}$ & $0.59 \pm 0.42$ & $4.10 \pm 0.78$ & $7.19 \pm 0.48$ & $5.26 \pm 1.01$ \\
\hline DB\#5 & $0.39 \pm 0.13$ & $3.44 \pm 0.55$ & $7.58 \pm 0.49$ & $5.77 \pm 0.99$ \\
\hline$f$ & 2.916 & 1.346 & 2.135 & .339 \\
\hline sig. & $.032 *$ & .268 & .339 & .850 \\
\hline Foot velocity & Preliminary & Kicking & MKF & Impact \\
\hline $\mathrm{PB}^{\# 1}$ & $0.25 \pm 0.33$ & $3.14 \pm 0.67$ & $9.38 \pm 0.93$ & $13.44 \pm 0.94$ \\
\hline $\mathrm{LB}^{\# 2}$ & $0.14 \pm 0.11$ & $3.27 \pm 0.55$ & $9.80 \pm 0.89$ & $11.46 \pm 0.98$ \\
\hline $\mathrm{CBS}^{\# 3}$ & $0.15 \pm 0.12$ & $3.21 \pm 0.89$ & $9.58 \pm 0.64$ & $11.59 \pm 1.45$ \\
\hline $\mathrm{SB}^{\# 4}$ & $0.41 \pm 0.36$ & $3.47 \pm 0.78$ & $9.38 \pm 0.72$ & $11.05 \pm 1.35$ \\
\hline $\mathrm{DB}^{\# 5}$ & $0.11 \pm 0.04$ & $2.87 \pm 0.54$ & $9.76 \pm 1.26$ & $13.05 \pm 1.87$ \\
\hline$f$ & 2.691 & 1.081 & .476 & .393 \\
\hline sig. & $.043^{*}$ & .377 & .753 & .813 \\
\hline Toe velocity & Preliminary & Kicking & MKF & Impact \\
\hline $\mathrm{PB}^{\# 1}$ & $0.11 \pm 0.05$ & $2.26 \pm 0.71$ & $9.83 \pm 1.15$ & $16.75 \pm 1.23$ \\
\hline $\mathrm{LB}^{\# 2}$ & $0.10 \pm 0.07$ & $2.52 \pm 0.72$ & $10.28 \pm 1.15$ & $15.12 \pm 1.34$ \\
\hline CBS\#3 & $0.12 \pm 0.09$ & $2.34 \pm 0.86$ & $10.10 \pm 0.80$ & $14.81 \pm 1.08$ \\
\hline $\mathrm{SB}^{\# 4}$ & $0.18 \pm 0.26$ & $2.34 \pm 0.82$ & $9.96 \pm 0.98$ & $14.43 \pm 1.43$ \\
\hline $\mathrm{DB}^{\# 5}$ & $0.10 \pm 0.06$ & $2.26 \pm 0.71$ & $10.49 \pm 1.87$ & $15.47 \pm 1.54$ \\
\hline$f$ & .712 & .186 & .540 & 2.095 \\
\hline sig. & .588 & .945 & .707 & .097 \\
\hline
\end{tabular}

In the table, the notation "\#n" indicates a significant level $(p<0.05)$ between the corresponding types. (Unit: Degrees/second)

*** $: p<0.001^{* *}: p<0.01$ 


\section{DISCUSSION}

This study aimed to quantitatively examine the effects of different footwork which was used for counterattack as the attack of the counterpart in a Taekwondo. This study was also to include both the counterattack footwork and kick in Taekwondo, because biomechanical researchers have not observed footwork variables which are the preparation of the kick execution as a counterattack skill. In this study, authors found that the footwork affected all temporal and spatial variables such as duration of the phases of the kick, center of mass displacement, body angles, and leg velocities.

First of all, the duration of time required increased as the back-step footwork distance increased. As shown in Figure 5, excluding the Reaction and Back-step phases which were for the preparation of kick, SB at Toe-off were the shortest from $0.08 \mathrm{sec}$, and DB, LB, CBS were longer starting from 0.16 to 0.17 sec. The smaller the distance of movement, the smaller the momentum when moving, and the participants kicked faster in SB after completing the footwork. In CBS and DB, in which footwork included two steps, unlike PB, LB, SB where footwork were completed by one step, duration of time required were the longest. The results of the center of mass displacement revealed an increase as the distance of the footwork increased. Also, the angle of the right knee decreased at the preliminary as the footwork distance increased, and it seems to be an effort to reduce the impact due to the increase of the momentum caused by longer backstep distance. More number of backsteps and longer backsteps have influenced the increase in preparation time required for roundhouse kicks and efforts should be made to shorten the time required when the Taekwondo athletes use long distance backsteps. In previous research which analyzed Taekwondo roundhouse kick biomechanically, Kim (2001) found that the preparation phase was 58\%, the bending(flexion) phase was 30\%, the kicking (extension) phase was 12\%, and Kang (1999) also revealed that the preparation phase was $67 \%$, the flexion phase was $22 \%$, the kicking phase was $11 \%$ as in this study. This means that the preparation time has a large portion of the roundhouse kick, and the time requred for roundhouse kick can be effectively reduced by making efforts to reduce preparation time. Moreover, the trunk angle reduced with the increasing backstep distance, and there were statistically significant differences at Preliminary and Kicking events. It was thought that bending the upper body forward is not a necessary posture because one of the hit targets, the face, can be exposed to the opponent. This finding provides a critical suggestion for coaches and practitioners. The Taekwondo athletes need to develop the ability to control the trunk angle at Kicking event with long footwork distance to avoid yielding a clean hit to the opponent. 
Second, velocity results show that thigh reached its maximum velocity before MKF, shin near MKF, and foot segment and toe reached maximum velocity just before Impact. The velocity of the increased leg was decelerated in the order of thigh, shin, foot, and toe, indicating that energy is transferred from the proximal segment to the distal segment. Putnam (1983) reported that during the initial phase of kick motion, the thigh rotation appeared larger than the shin rotation, but later the thigh rotation decreased and the shin rotation increased and the same results were obtained in this study. About these results, Yoon (1997) stated that the momentum is transferred from the thigh to the shin, and Kim (1993) explained by the segmentation theory of Plagenhoef (1971) and Bunn (1972). Also, Kim (1991) reported that it was a whip-like movement. In addition, at the Impact event, it is thought that the joint was fixed and the moment of the toe is effectively transferred to the target by minimizing the multi-segments temporarily resulting in maximizing the mass.

One limitation of the current study was that the footwork were predetermined and kept on unaltered during the kick execution. In a sparring match, both competitors are continuously sliding or stepping forwardbackward and left-right to react and execute the counterattack. As a result, the type of footwork can change during the execution of the kick, which requires the attacking contender to adjust the footwork motion to compensate for the opponent's move. Future studies need to conduct a more realistic footwork condition scheme such as execution of counterattack with side footwork after real systematic alteration of attacking.

\section{Conclusions}

Summarizing the above, as the footwork distance increases, the center of the body becomes lower, and the kick-leg can increase the foot speed by using the ground reaction force of the kick-leg and the center of the mass movement; however, it is likely to be vulnerable to the attack of the opponent. On the contrary, if the footwork distance was reduced, the time required for footwork was short, which may lead to a quick counterattack, but it could be exposed to the range of the opponent's attack, and the effective foot speed for the counterattack will not be obtained. Therefore, it would be necessary to make efforts to compensate for the strengths and weaknesses of the types so as to invalidate the opponent's attack and to increase the contribution of each body segment.

\section{REFERENCES}

Abdel-Aziz, Y.I., Karara, H.M., \& Hauck, M. (2015) Direct Linear Transformation from Comparator Coordinates into Object Space Coordinates in Close-Range 
Photogrammetry. Photogrammetric Engineering \& Remote Sensing, 81(2), 103-107.

Bunn, J.W., Scientific principles of coaching. 2d ed. Englewood Cliffs, N.J., Prentice-Hall, 1972.

Estevan, I., Alvarez, O., Falco, C., Molina-Garcia, J., \& Castillo, I. (2011) Impact force and time analysis influenced by execution distance in a roundhouse kick to the head in taekwondo. The Journal of Strength and Conditioning Research, 25(10), 2851-6.

Estevan, I., Falco, C., \& Jandacka, D. (2011) Mechanical analysis of roundhouse kick according to the stance position. A pilot study. Portuguese Journal of Sport Sciences, 11, 215-218.

Estevan, I., Falco, C., Alvarez, O., \& Molina-García, J. (2012) Effect of olympic weight category on performance in the roundhouse kick to the head in taekwondo. Journal of Human Kinetics, 31, 37-43.

Estevan, I., Freedman-Silvernail, J., Jandacka, D., \& Falco, C. (2016). Segment coupling and coordination variability analyses of the roundhouse kick in taekwondo relative to the initial stance position. Journal of Sports Sciences, 34, 1766- 1773. DOI:10.1080/02640414.2015.1137342

Falco, C., Alvarez, O., Castillo, I., Estevan, I., Martos, J., Mugarra, F., \& Iradi, A. (2009) Influence of the distance in a roundhouse kick's execution time and impact force in Taekwondo. Journal of Biomechanics, 42, 242-248.

Kang, S. (1999) Analysis of the patterns of the Biomechanical Characteristics in Taekwondo Kicking Techniques. (Doctoral dissertation, Sungkyunkwan University, Seoul Korea).

Kazemi, M., G. Perri, \& D. Soave (2010) A profile of 2008 Olympic Taekwondo competitors. The Journal of the Canadian Chiropractic Association, 54(4), 243-9.

Kim, B. (1991) The effect of Tae kwon do dolryeochagi according to leg position. (Master thesis, Seoul National University, Seoul Korea).

Kim, J. W., Kwon, M. S., Yenuga, S. S., \& Kwon, Y. H. (2010) The effects of target distance on pivot hip, trunk, pelvis, and kicking leg kinematics in Taekwondo roundhouse kicks. Sports Biomechanics, 9(2), 98-114.

Kim, S. (1993) Classification of kinematical movement pattern in Taekwondo kicking techniques. (Doctoral dissertation, Yonsei University, Seoul Korea).

Kim, S.H., Chung, K.H., \& Lee, K.M. (1999) Taekwondo Kyorugi: Olympic Style Sparring. Turtle Press.

Kim, W. (2001) The effect of the biomechanical factors of the Apdollyo-chagi in Tae Kwon Do on the kicking foot. (Doctoral dissertation, Sungkyunkwan University, Seoul Korea). 
Koh, J.O. \& Watkinson, E.J. (2002) Video analysis of blows to the head and face at the 1999 World Taekwondo Championships. The Journal of Sports Medicine and Physical Fitness, 42(3), 348-53.

Kong, P.W., Luk, T.C., \& Hong, Y. (2000) Difference between Taekwondo roundhouse kick executed by the front and back leg. Proceedings of XVIII International symposium on biomechanics in sports, Hong Kong, Department of Sports Science and Physical Education. The Chinese University of Hong Kong, p.268.

Liu, P., Tan, J., An, J., \& Wang, G. (2000) A kinematic analysis of round kick in taekwondo. Proceedings of XVIII International symposium on biomechanics in sports, Hong Kong, Department of Sports Science and Physical Education. The Chinese University of Hong Kong, p.916-919.

Menescardi, C., Lopez-Lopez, J. A., Falco, C., Hernandez-Mendo, A., \& Estevan, I. (2015) Tactical aspects of a National University Taekwondo Championship in relation to round and match outcome. The Journal of Strength and Conditioning Research, 29(2), 466-71.

Oh, C.H. \& Choi, S.N. (2004) A kinematic analysis on reverse-turning kick of Taekwondo student-athletes. Korean Journal of Sport and Leisure Studies, 22, 497-509.

Pieter, F. \& Pieter, W. (1995) Speed and force in selected taekwondo techniques. Biology of Sport, 12(4). 257-266.

Plagnhoef, S. (1971) Patterns of Human motion. Englewood Cliffs, HJ PrenticeHall.

Putnam, C.A. (1983) Interaction between segments during a kicking motion. In $\mathrm{H}$. Matsui \& K. Kobayashi(Eds.) Biomechanics ?-B, 688-694.

Shin, J.M. \& Choi, J.Y. (2001) The comparison of relative motion of distal segment about proximal segment of Dolyeochagi in Taekwondo. Korean Journal of Sport and Leisure Studies, 15, 545-556.

Tang, W.T., Chang, J.S, \& Nien, Y.H. (2007) The kinematics characteristics of preferred and non-preferred roundhouse kick in elite taekwondo athletes. Journal of Biomechanics, 40(Supplement 2), S780.

Yang, C. (1999) Effect of target height on biomechanical factors during Taekwondo and Hapkido Dollyuchage motion. (Doctoral dissertation, Kookmin University, Seoul Korea).

Yoon, C. (1997) Contribution of body segment to foot velocity in Tae Kwon Do kicking motion. (Master thesis, Seoul National University, Seoul Korea). 